\title{
Association Between ABO Blood Group and Malaria Infection and Ownership and Utilization of Long- Lasting Insecticide-Treated Nets Among School Children in North Bank Area of Makurdi, Nigeria.
}

\author{
VIictor Ugochukwu Obisike ${ }^{1 *}$ and Thomas Orji Makwe ${ }^{2}$ \\ ${ }^{1}$ Department of Animal and Environmental Biology, Abia State University Uturu, Abia Nigeria \\ ${ }^{2}$ Bioresources Development Center (National Biotechnology Development Agency), Abagana, Anambra Nigeria
}

Corresponding author: VIictor Ugochukwu Obisike, Department of Animal and Environmental Biology, Abia State University Uturu, Abia Nigeria

\section{ARTICLE INFO}

Received: 慧 September 26, 2020

Published: October 16, 2020

Citation: Vlictor Ugochukwu Obisike, Thomas Orji Makwe. Association Between ABO Blood Group and Malaria Infection and Ownership and Utilization of LongLasting Insecticide-Treated Nets Among School Children in North Bank Area of Makurdi, Nigeria. Biomed J Sci \& Tech Res 31(2)-2020. BJSTR. MS.ID.005070.

\section{ABSTRACT}

Studies have related blood group and some infectious diseases. The relationships between malaria infection and blood group have been studied over time, but they are in contrast with each other. Therefore, the need to carry-out the research in Makurdi as malaria has being one of the major causes of child mortality among pupils. Rapid One Step Malaria Ag. HRP2 Card Test was used to test for malaria while Smar kit was used to determine different blood groups. A total of 150 school children were sampled in North Bank area of Makurdi between June and July 2014. Out of 152 school children used in the study, 127 were positive to malaria infection, the blood group distribution was in the ratio of $32,38,7$ and 73 for blood groups A, B, AB and 0 respectively. Blood groups A and B had the highest prevalence of malaria while the least were in $O$ and $A B$. Only $70(46.7 \%)$ of the students had LLINS and only $30 \%$ of the owners do sleep under LLINS.

Keywords: Environment; Antibodies; Carbohydrate; Infectious Disease; Blood Sample; Plasmodium; Antigens; P. falciparium

\section{Introduction}

Several researches have shown the relationship between $\mathrm{ABO}$ blood group and infectious diseases [1]. Malaria has been one of the deadliest diseases in the tropics and sub tropics [2]. Malaria control has been a difficult task in the tropics mainly due to the environmental conditions that favour the Mosquito vector. The ABO blood groups consist of A, B and $\mathrm{H}$ carbohydrate antigens which can regulate protein activities during infection and antibodies against these antigens [3]. A number of studies have reported contradictory reports on significant association between $\mathrm{ABO}$ blood group system and some disease conditions, the studies reviewed the impact of ABO blood group on infection status of individuals [4]. However, other studies have shown that high frequency of malaria has been observed among blood group 'A' individuals as compared with oth er blood group individuals. Large numbers of severe malaria cases were also reported among blood group 'A' individuals [5].

\section{Material and Method}

The research was carried out in North Bank Area of Makurdi Benue Nigeria (Figure 1). Blood sample was collected using lancet as described in the RDT AG HRP2 CARD TEST manual as follows:

The thump was cleaned with an alcohol swab. The end of the fingertip was squeezed and pierced with sterile lancet. The first drop of blood was wiped away with cotton. The pierced fingertip was squeezed gently, and sample pipette was used to collect $10 \mu$ lof blood. The test device was placed on a flat surface and labeled with student's identification number and $5 \mu$ l blood was added into the 
sample well of the respective Test Device. Two drops ( $60 \mu \mathrm{l})$ of Assay Diluent was added to Assay Diluent well. The result was read within 20 minutes. The remaining portion of blood was dropped in four different glass slides labeled $\mathrm{A}, \mathrm{B}, \mathrm{AB}$ and $\mathrm{D}$ and respective Antigens were added as described in the manufacturer's manual for $\mathrm{ABO}$ blood grouping. The result was read in 5 minutes and interpreted $[6]$.

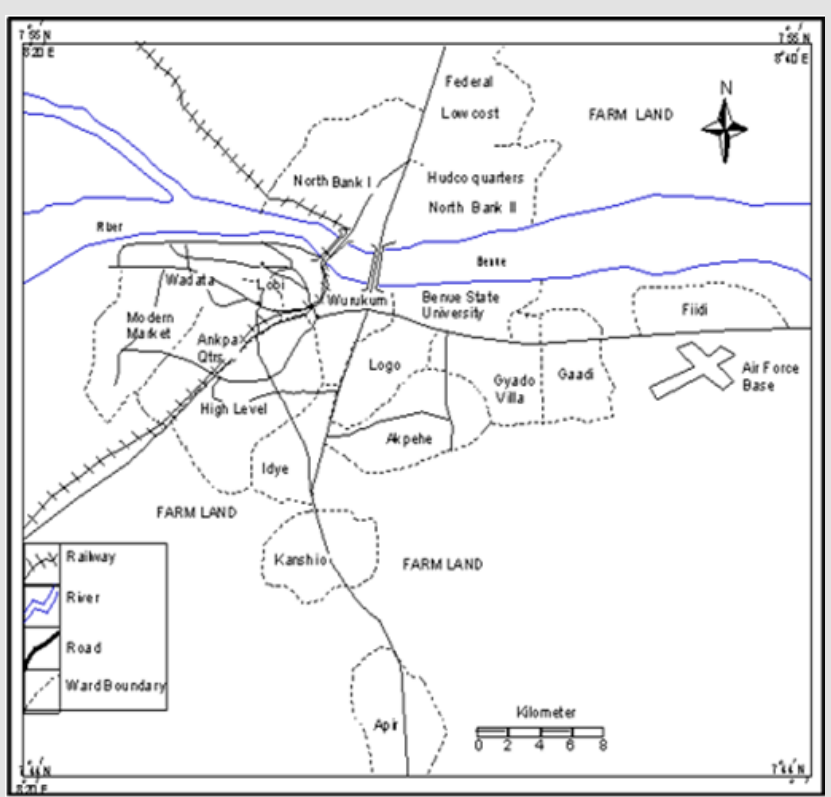

Figure 1: Map of Makurdi

\section{Results}

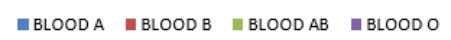

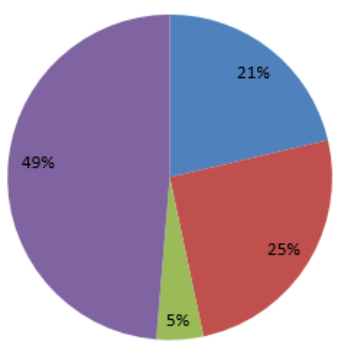

Figure 2: Shows Percentage Distribution of Blood Group among the Students

In the study to ascertain the relationship between $\mathrm{ABO}$ blood group and Plasmodium falciparium infection using Smart diagnosis Blood grouping reagent Test and Smart Rapid Diagnosis Test Kits among school children in North bank area of Makurdi, Benue State, Blood groups $\mathrm{A}, \mathrm{B}, \mathrm{AB}$, and $\mathrm{O}$ were present in the study population in the ratio of 4.5:5.4:1:10.4 respectively. Out of 152 school children sampled, 127 were positive to malaria infection while only 2 students were negative to the test and 2 results showed invalid.
Children with blood group A, B, AB and 0 were 32, 38, 7 and 73 respectively. Figure 2 shows percentage distribution of blood group among the students while Figure 3 shows malaria infection. The prevalence was as follows for P.falciparium infection $21.1 \%$, $25 \%, 4 \%$ and $48 \%$ for blood groups $\mathrm{A}, \mathrm{B}, \mathrm{AB}$ and 0 respectively (Table 1). There were no significant different in relation to blood group malaria infection ( $\mathrm{P}>0.05)$. with respect to Long Lasting Insecticide-treated Nets (LLINs) ownership and usage, $46.7 \%$ of the students had LLINS and only $30 \%$ of the owners do sleep under LLINS (Table 2).

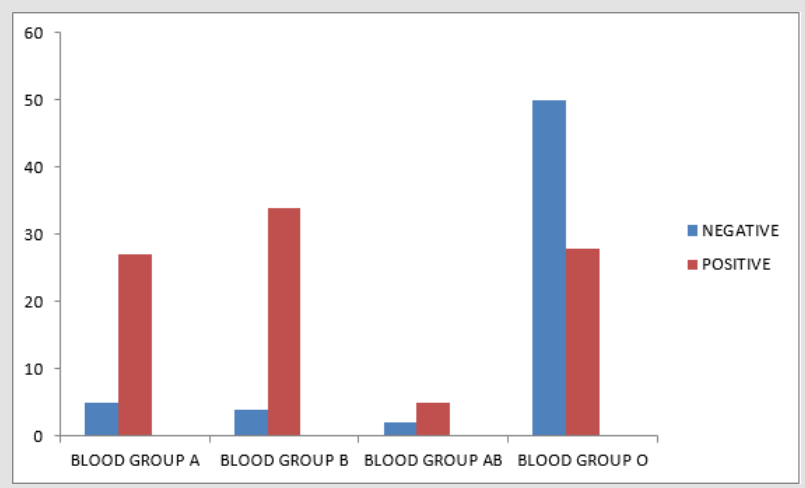

Figure 3: Malaria infection with respect to blood group

Table 1: Blood group distribution by Age of students

\begin{tabular}{|c|c|c|c|c|}
\hline \multirow{2}{*}{$\begin{array}{c}\text { Blood } \\
\text { group }\end{array}$} & \multicolumn{3}{|c|}{ Age } & \multirow{2}{*}{ Total } \\
\cline { 2 - 4 } & $\mathbf{5 - 9}$ & $\mathbf{1 0 - 1 4}$ & $\mathbf{2 1 5}$ & \\
\hline $\mathrm{A}$ & 8 & 16 & 8 & 32 \\
\hline $\mathrm{B}$ & 9 & 10 & 19 & 38 \\
\hline $\mathrm{AB}$ & 2 & 1 & 4 & 7 \\
\hline 0 & 16 & 21 & 36 & 73 \\
\hline
\end{tabular}

Table 2: Age related single infection / Blood group

\begin{tabular}{|c|c|c|c|c|}
\hline \multirow{2}{*}{ Blood group } & \multicolumn{3}{|c|}{ Age } & \multirow{2}{*}{ Total } \\
\cline { 2 - 5 } & $\mathbf{5 - 9}$ & $\mathbf{1 0 - 1 4}$ & $\mathbf{1 1 5}$ & \\
\hline A & 4 & 10 & 7 & 21 \\
\hline B & 5 & 15 & 22 & 42 \\
\hline AB & 0 & 1 & 4 & 5 \\
\hline O & 11 & 21 & 27 & 59 \\
\hline Total & 20 & 47 & 60 & 127 \\
\hline
\end{tabular}

\2 $\mathrm{Cal}=5.271, \mathrm{df}=6, \mathrm{p}>0.05$

\section{Discussion}

The result of our study is an indication that individual susceptibility to malaria parasite mainly Pffalciparium varies according to blood group, the cause of the variance is yet to be ascertained though there are some suggestions firstly variations in genetic makeup of the individual and variations in chemical structure of the receptor sites of the erythocytic of the various blood 
groups of an individual may cause the variation in susceptibility to Plasmodium infection. This study revealed that blood group 0 had $48 \%$ of the total population which indicates its high abundance in areas where malaria infection in endemic, this is in support of previous work by Christine and Walter in 2007 [7] which states that the ratio of group $\mathrm{O}$ to $\mathrm{A}$ is higher in geographic regions where malaria is currently endemic'. Also, the role of group A and $B$ antigens in cytoadherence rosette formation with P. falciparum erythrocytes membrane protein (PfEMP-1) than in blood group 0 may explain why group A and B individual are prone to malaria infection [3] this could suggest a higher rate of survival from malaria among individuals associated with blood group A and B which agrees with Uneke, et al. [8].

In terms of prevalence of malaria infection with respect to blood groups, groups A and B had 50\% infection in school children below 10 years of age while group 0 of the same age range had $40 \%$ infections, this agrees with earlier report by Williams in 2006 [9] and also that of Christine and Walter in 2007 [7], which revealed that many polymorphic human genes are implicated when it comes to the in the determination of infectivity or resistance to Plasmodium infection to some extent which may include blood group A and 0 respectively, this also agrees with previous study in Taraba Nigeria [10] which stated that Blood group A was more significantly infected than other blood groups, followed by blood group B and least infected was blood group 0 . Blood group AB had a low prevalence infection as in blood group 0 . the results suggests a slight resistance to malaria infection in blood groups $\mathrm{AB}$ and 0 . This is in contrast to report by Williams in 2006 [9] which gave higher rate of infection in blood group 0 . This is an indication that blood group A is a risk factor for severe malaria while blood group 0 may provide some form of protection against malaria; this is in agreement with work done by Senga et al. in 2007 [10]. The overall prevalence was as follows $34 \%$ for blood groups A and B while AB and 0 had 28.65 and $28.8 \%$ respectively.

However, correlation is significant at 0.01 between $\mathrm{ABO}$ blood group and P. falciparium infection. This suggests a strong positive relationship between blood group and malaria infection, which is in contrast with work of Burhan, et al. [11] which suggested no association between blood group and malaria infection. The agerelated infection showed that age group 10-14 had the highest prevalence of malaria infection; this could be implicated with the number of hours the age group stays out thereby exposing the group to mosquito bite. This is because this group is very active house-hold chores which most often make them stay out late. Next to this age group in prevalence is 15years and above, this could also be likened to the above reasons.

\section{Ownership /Usage of Long Lasting Insecticide-treated Nets}

With respect to ownership of Long Lasting Insecticide-treated Nets (LLINs), only 70 (46.7\%) of the students had LLINs as that time of this study, while a larger population (53.3\%) of the study had no LLINs. This was despite the free distribution of LLINs ongoing in the area as at that period. Surprisingly, only 21 (30\%) out of the owners of LLINs actually sleep in it. Further [robbing identified some discomforts such as heat, the odor of the fabrics as reasons for non-usage. Some also believed that LLINs are used to preserve corpses therefore, they cannot sleep in it.

\section{Conclusion}

The result of this study showed a higher rate of malaria infection in school children with ABO Blood group 'A' and 'B'. It was also discovered that most of the students do not sleep under insecticide treated nets.

\section{Acknowledgement}

We sincerely wish to acknowledge the school authorities and students especially Benlad Model Secondary School North Bank Makurdi Benue State Nigeria and others for their support during the study.

\section{References}

1. Deepa, Alwar VA, Karuna Rameshkumar, Ross C (2011) ABO blood groups and malaria related clinical outcome. Journal of vector Borne Dis 48(1): 7-11

2. Guptaa M, Rai Chowdhuru AN (1980) Relationship between ABO Blood group and Malaria. Bulletin of the World Health Organization 58(6): 913-915.

3. Degarege A, Medhin G, Animut A, Legess M, Erko B (2012) Association of $\mathrm{ABO}$ blood group and P. falciparum malaria related outcomes: acrosssectional study in Ethiopia. Acta Trop 123(3): 164-169.

4. Gayathri BN, Harendra Kumar ML, Gomathi N, Jeevan Shetty, Reethesh RP (2013) Relationship between ABO blood groups and malaria with clinical outcome in rural area of South India. Global Journal of Medicine and Public Health 2(1): 1-7.

5. (2012) World Health Organization (WHO). World Malaria Report.

6. Wood CS, Harrison GA, Dore C, Weiner JS (1972) Selective feeding of Anopheles gambiae according to $\mathrm{ABO}$ blood group status. Nature 239(5368): 165.

7. Christine MC, Walter HD (2007) The ABO blood system and Plasmodium falciparum. J Amer Soc Haematol 110(7): 2250-2258.

8. Uneke CJ, Ogbu O, Nwojiji V (2006) Potential risk of induced malaria by blood transfusion in Southeastern Nigeria. Mc Gill J Med 9(1): 8-13.

9. Williams TN (2006) Human red blood cell polymorphisms and malaria. Current Opin Microbiol 9(4): 388-396.

10. TIDI SK, Amos JT, Firyanda E (2013) Association between Plasmodium infection, Haemoglobin genotypes and Blood groups among Under-five nomadic Fulani of Northeastern Nigeria. International journal of malaria research and reviews 1(2): 7-11.

11. Burhan H, Hasan AS, Mansur UI Hague S, Zaidi G, Shaikh I, et al. (2016) Association between Blood Group and Susceptibility to Malaria and its Effects on Platelets, TLC and HB. Journal of infectious Diseases of Developing Countries 10(10): 1124-1128. 


\section{ISSN: 2574-1241}

DOI: 10.26717/BJSTR.2020.31.005070

Vlictor Ugochukwu Obisike. Biomed J Sci \& Tech Res

(c) (P) This work is licensed under Creative Commons Attribution 4.0 License

Submission Link: https://biomedres.us/submit-manuscript.php

\begin{tabular}{ll} 
BIOMEDICAL & Assets of Publishing with us \\
RESEARCHES & - Global archiving of articles \\
& - Immediate, unrestricted online access \\
\hline - Rigorous Peer Review Process
\end{tabular}

